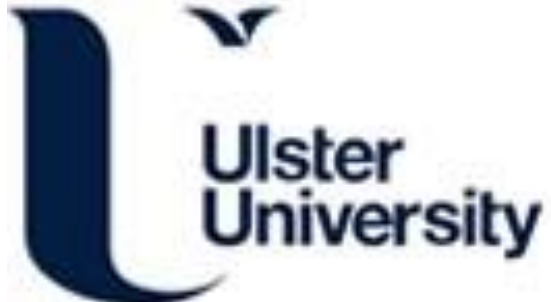

Motion Detection Using Spiking Neural Network Model

Wu, Q., McGinnity, TM., Maguire, LP., Cai, J., \& Valderrama, G. (2008). Motion Detection Using Spiking Neural Network Model. In Unknown Host Publication (pp. 76-83). Springer. https://doi.org/10.1007/978-3-540-859840_10

Link to publication record in Ulster University Research Portal

\section{Published in:}

Unknown Host Publication

Publication Status:

Published (in print/issue): 18/09/2008

DOI:

10.1007/978-3-540-85984-0_10

\section{Document Version}

Publisher's PDF, also known as Version of record

\section{General rights}

Copyright for the publications made accessible via Ulster University's Research Portal is retained by the author(s) and / or other copyright owners and it is a condition of accessing these publications that users recognise and abide by the legal requirements associated with these rights.

\section{Take down policy}

The Research Portal is Ulster University's institutional repository that provides access to Ulster's research outputs. Every effort has been made to ensure that content in the Research Portal does not infringe any person's rights, or applicable UK laws. If you discover content in the Research Portal that you believe breaches copyright or violates any law, please contact pure-support@ulster.ac.uk. 


\title{
Motion Detection Using Spiking Neural Network Model
}

\author{
QingXiang $\mathrm{Wu}^{12}$, Martin McGinnity ${ }^{1}$, Liam Maguire ${ }^{1}$, Jianyong Cai ${ }^{2}$, German \\ Valderrama $^{1}$ \\ ${ }^{1}$ School of Computing and Intelligent Systems, University of Ulster at Magee Campus \\ Derry, BT48 7JL, Northern Ireland, UK \\ \{q.wu, tm.mcginnity, lp.Maguire, g.valderrama \}@ulster.ac.uk \\ ${ }^{2}$ School of School of Physics and OptoElectronic Technology, Fujian Normal University \\ Fuzhou, 350007, China \\ E-mail:\{qxwu; cjy\}@fjnu.edu.cn
}

\begin{abstract}
Inspired by the behaviour of the human visual system, a spiking neural network is proposed to detect moving objects in a visual image sequence. The structure and the properties of the network are detailed in this paper. Simulation results show that the network is able to perform motion detection for dynamic visual image sequence. Boundaries of moving objects are extracted by the spiking neural network. Using the boundary, a moving object filter is created to take the moving objects from the grey image. The moving object images can be used to recognise moving objects. The moving tracks can be recorded for further analysis of behaviours of moving objects. It is promising to apply this approach to video processing domain and robotic visual systems.
\end{abstract}

Key words: Motion detection, spiking neural networks, visual system.

\section{Introduction}

A football player can promptly perform a series of actions to capture a football when he sees the moving football toward him. The information of the moving football conveys to the brain through the visual system. The retina contains complex circuits of neurons that extract salient information from visual inputs. Signals from photoreceptors are processed by retinal interneurons, integrated by retinal ganglion cells and sent to the brain by axons of retinal ganglion cells. Different cells respond to different visual features, such as light intensity, colour or moving objects [1-5]. Mammalian retinas contain approximately 55 distinct cell types, each with a different function [1]. A retinal cell type responds to upward motion has been identified in [6]. Results in [7] demonstrate that information for segmenting scenes by relative motion is represented as early as V1. To detect moving objects, the brain must distinguish local motion within the scene from the global image. The findings in [8] show how a population of ganglion cells selective for differential motion can rapidly flag moving objects, and even segregate multiple moving objects. In [9], it is shown that neurons 
compute internal models of the physical laws of motion. These findings are shown some principles for the brain to detect moving objects in the psychological or statistical level. What are the exact neuronal circuits for motion detection? How can we simulate the neuronal circuits in electronic circuits and then apply them to artificial intelligent systems? This is the motivation of this paper. Jeffress [22-24] applied the time difference principle of axonal delay to account for sound localisation [11,13]. Based on spiking neuron model and axonal delay [10-14], a neuronal circuit is proposed to explain how a spiking neural network can detect moving objects in an image sequence. The neuronal circuit has been simulated in software and embedded in a simulation system. Combining with the traditional image processing approaches, the system can demonstrates retrieval of moving objects from an image sequence.

The remainder of this paper is organized as follows. In Section 2, axonal delays are used to construct a spiking neural network which is used to simulate the visual cortex for motion detection, and the principle of motion detection based on spiking neurons is described. The network model is based on conductance-based integrateand-fire neurons. The behaviours of the neural network with the axonal delay are represented by a set of equations in Section 3. Simulation system and results for motion detection are presented in Section 4. Discussions about the network are given in Section 5.

\section{Spiking Neural Network Model for Motion Detection}

The human visual system performs motion detection very efficiently. Neuroscientists have found that there are various receptive fields from simple cells in the striate cortex to those of the retina and lateral geniculate nucleus (see page 236-248 in [15]), and the axonal delay causes a phase shift for a spike train [10-14]. Inspired by the axonal delay mechanism, a spiking neural network model is proposed to detect moving objects. Its structure is shown in Fig. 1. Suppose that the first layer represents photonic receptors for an image. Each pixel of the image corresponds to a receptor. The intermediate layer is composed of two neuron arrays. N1 neuron array and N2 neuron array have the same size as the receptor layer. N1 and N2 neuron array are connected to neurons in output layer. As shown in Fig.1, the neuron $\operatorname{Nr}(x, y)$ is connected to $\mathrm{N} 1(\mathrm{x}, \mathrm{y})$ through excitatory synapse without delay and through inhibitory synapse with an axonal delay $\Delta \mathrm{t}$. Let $\mathrm{S}_{\mathrm{Nr}}(\mathrm{x}, \mathrm{y}, \mathrm{t})$ represent current from receptor $\operatorname{Nr}(\mathrm{x}, \mathrm{y})$. If the current from receptor $\operatorname{Nr}(\mathrm{x}, \mathrm{y})$ is stable, i.e. current $\mathrm{S}_{\mathrm{Nr}}(\mathrm{x}, \mathrm{y}, \mathrm{t})$ is equal to current $\mathrm{S}_{\mathrm{Nr}}(\mathrm{x}, \mathrm{y}, t-\Delta t)$, the excitatory input and the inhibitory input of neuron $\mathrm{N} 1(\mathrm{x}, \mathrm{y})$ can be balanced by adjusting the parameters of synapses, and then neuron $\mathrm{N} 1(\mathrm{x}, \mathrm{y})$ is silent. If the current of receptor $\mathrm{Nr}(\mathrm{x}, \mathrm{y})$ becomes stronger, i.e. the current $\mathrm{S}_{\mathrm{Nr}}(\mathrm{x}, \mathrm{y}, t)$ is larger than current $\mathrm{S}_{\mathrm{Nr}}(\mathrm{x}, \mathrm{y}, \mathrm{t}-\Delta t)$, the balance is broken, and then neuron $\mathrm{N} 1(\mathrm{x}, \mathrm{y})$ will generate spikes if $\mathrm{S}_{\mathrm{Nr}}(\mathrm{x}, \mathrm{y}, t)$ is larger enough than $\mathrm{S}_{\mathrm{Nr}}(\mathrm{x}, \mathrm{y}, \mathrm{t}-\Delta t)$. If the current of receptor $\operatorname{Nr}(\mathrm{x}, \mathrm{y})$ becomes weaker, neuron $\mathrm{N} 1(\mathrm{x}, \mathrm{y})$ does not fire. In this case, neuron $\mathrm{N} 2(\mathrm{x}, \mathrm{y})$ will fire if $\mathrm{S}_{\mathrm{Nr}}(\mathrm{x}, \mathrm{y}, t)$ is smaller enough than $\mathrm{S}_{\mathrm{Nr}}(\mathrm{x}, \mathrm{y}, \mathrm{t}-\Delta t)$. Therefore, the moving pixels are reflected in the output neuron layer, i.e. Neuron $\mathrm{N}\left(\mathrm{x}^{\prime}, \mathrm{y}^{\prime}\right)$ will fire if Neuron $\mathrm{N} 1$ or Neuron N2 fires. 


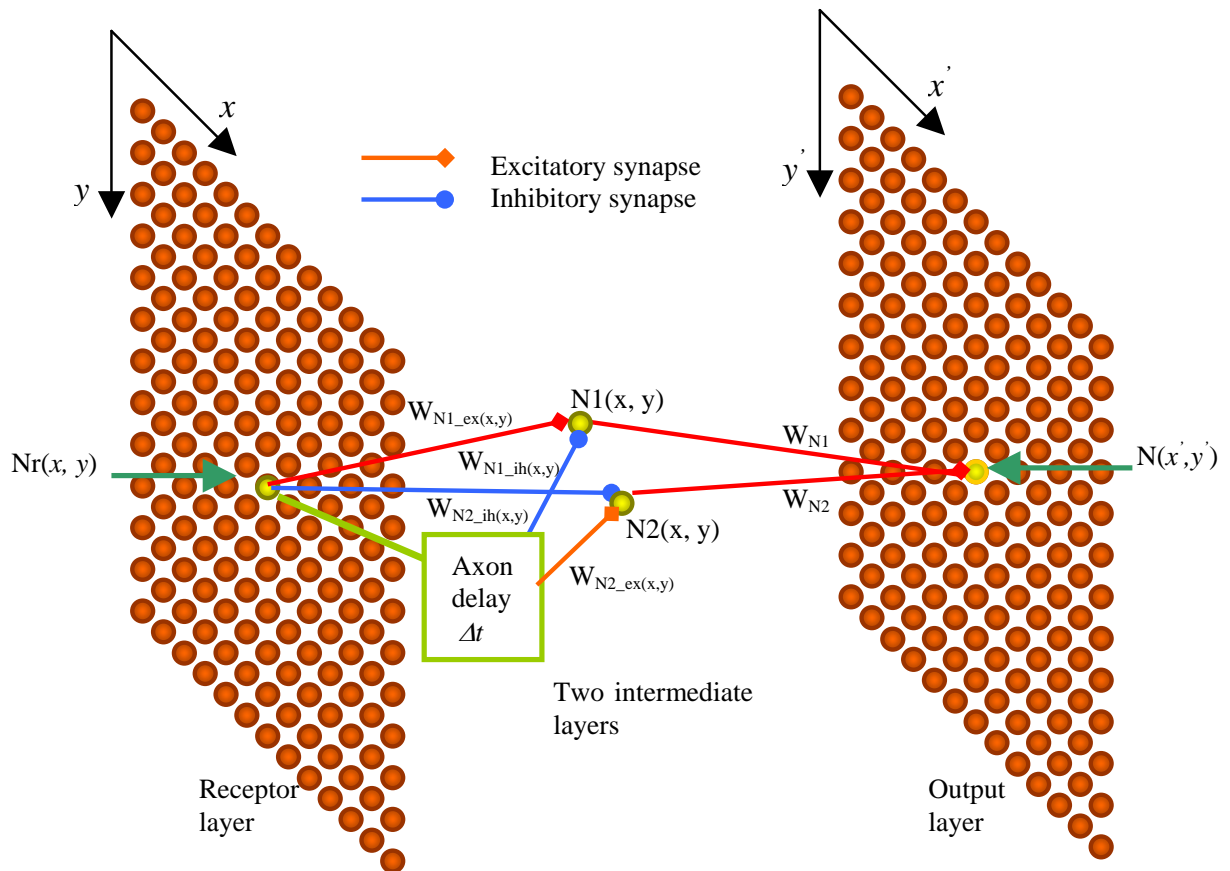

Fig. 1. Spiking neural network model for motion detection

\section{Spiking Neuron Model and Simulation Algorithms}

Simulation results show that the conductance based integrate-and-fire model is very close to the Hodgkin and Huxley neuron model [16-21]. The conductance based integrate-and-fire model is applied to the aforementioned network model. Let $\mathrm{G}_{x, y}(t)$ represent gray scale at time $t$ at point $(x, y)$ in the image, $q_{x, y}^{e x}(t)$ represent peak conductance caused by excitatory current $\mathrm{S}_{\mathrm{Nr}}(\mathrm{x}, \mathrm{y}, \mathrm{t})$ from a receptor at point $(x, y)$, and $q_{x, y}^{i h}(t)$ represent peak conductance caused to inhibitory current $\mathrm{S}_{\mathrm{Nr}}(\mathrm{x}, \mathrm{y}, \mathrm{t})$ from a receptor at point $(x, y)$. For simplicity, suppose that each receptor can transform a value of gray scale to peak conductance by the following expressions.

$$
q_{x, y}^{e x}(t)=\alpha G_{x, y}(t) ; \quad q_{x, y}^{i h}(t)=\beta G_{x, y}(t)
$$

where $\alpha$ and $\beta$ are constants. According to the conductance based integrate-and-fire model [20-21], neuron N1 is governed by the following equations.

$$
\frac{d g_{N 1 \_e x(x, y)}(t)}{d t}=-\frac{1}{\tau_{e x}} g_{N 1 \_e x(x, y)}(t)+\alpha G_{x, y}(t) .
$$




$$
\begin{gathered}
\frac{d g_{N 1 \_i h(x, y)}(t)}{d t}=-\frac{1}{\tau_{i h}} g_{N 1_{-} i h(x, y)}(t)+\beta G_{x, y}(t) . \\
c_{m} \frac{d v_{N 1(x, y)}(t)}{d t}=g_{l}\left(E_{l}-v_{N 1(x, y)}(t)\right)+\frac{w_{N 1 \_e x(x, y)} g_{N 1 \_e x(x, y)}(t)}{A_{e x}}\left(E_{e x}-v_{N 1(x, y)}(t)\right) \\
+\frac{w_{N 1 \_i h(x, y)} g_{N 1 \_i h(x, y)}(t-\Delta t)}{A_{i h}}\left(E_{i h}-v_{N 1(x, y)}(t)\right),
\end{gathered}
$$

where $g_{N 1 \_e x(x, y)}(t)$ and $g_{N 1 \_i h(x, y)}(t)$ are the conductance for excitatory and inhibitory synapses respectively, $\tau_{e x}$ and $\tau_{i h}$ are the time constants for excitatory and inhibitory synapses respectively, $\Delta t$ is the axonal delay, $v_{N 1(x, y)}(t)$ is the membrane potential of neuron $N 1, E_{e x}$ and $E_{i h}$ are the reverse potential for excitatory and inhibitory synapses respectively, $c_{m}$ represents a capacitance of the membrane, $g_{l}$ represents the conductance of membrane, ex is short for excitatory and ih for inhibitory, $A_{e x}$ is the membrane surface area connected to a excitatory synapse, and $A_{i h}$ is the membrane surface area connected to a inhibitory synapse, $w_{N 1 \_i h(x, y)}$ represents the strength of inhibitory synapses, $w_{N 1 \_} e x(x, y)$ represents the strength of excitatory synapses. $w_{N 1 \_i h(x, y)}$ and $w_{N 1 \_e x(x, y)}$ are adjusted so that neuron $\mathrm{N} 1$ dose not fire when $G_{x, y}(t)=G_{x, y}(t-\Delta t)$.

By analogy, membrane potential of Neuron $\mathrm{N} 2$ is governed by an equation as follows.

$$
\begin{gathered}
c_{m} \frac{d v_{N 2(x, y)}(t)}{d t}=g_{l}\left(E_{l}-v_{N 2(x, y)}(t)\right)+\frac{w_{N 2 \_e x(x, y)} g_{N 2 \_e x(x, y)}(t-\Delta t)}{A_{e x}}\left(E_{e x}-v_{N 2(x, y)}(t)\right) \\
+\frac{w_{N 2 \_i h(x, y)} g_{N 2 \_i h(x, y)}(t)}{A_{i h}}\left(E_{i h}-v_{N 2(x, y)}(t)\right)
\end{gathered}
$$

where $v_{N 2(x, y)}(t)$ represents the membrane potential of neuron $\mathrm{N} 2$. Note that changes of conductance of excitatory synapses have a delay comparing with Neuron N1, but changes of conductance of inhibitory synapses have not any delay that is different from Neuron N1.

When the membrane potential of Neuron N1 and N2 reaches a threshold $v_{t h}$ the neuron generates a spike respectively. These spikes are transferred to corresponding neuron in output layer. Let $S_{\mathrm{N} 1}(t)$ represent a spike train which is generated by neuron N1.

$$
S_{N 1}(t)= \begin{cases}1 & \text { if neuron } N 1 \text { fires at timet. } \\ 0 & \text { if neuron N1does not fire at timet }\end{cases}
$$


By analogy, let $S_{\mathrm{N} 2}(t)$ represent spike trains for neurons N2. Neuron $N_{x^{\prime}, y^{\prime}}$ in the output layer is governed by the following equations.

$$
\begin{gathered}
\frac{g_{e x\left(x^{\prime}, y^{\prime}\right)}(t)}{d t}=-\frac{1}{\tau_{e x}} g_{e x\left(x^{\prime} y^{\prime}\right)}(t)+\left(w_{N 1} S_{N 1}(t)+w_{N 2} S_{N 2}(t)\right) . \\
c_{m} \frac{d v_{x^{\prime}, y^{\prime}}(t)}{d t}=g_{l}\left(E_{l}-v_{x^{\prime}, y^{\prime}}(t)\right)+\frac{g_{e x\left(x^{\prime}, y^{\prime}\right)}(t)}{A_{e x}}\left(E_{e x}-v_{x^{\prime}, y^{\prime}}(t)\right) .
\end{gathered}
$$

Note that Neuron $N_{x^{\prime}, y^{\prime}}$ is connected to intermediate neurons only by excitatory synapses. Let $S_{x^{\prime}, y^{\prime}}(t)$ represent spike train generated by Neuron $N_{x^{\prime}, y^{\prime}}$ in output layer. The firing rate for Neuron $N_{x^{\prime}, y}$, is calculated by the following expression.

$$
r_{x^{\prime}, y^{\prime}}(t)=\frac{1}{T} \sum_{t}^{t+T} S_{x^{\prime}, y^{\prime}}(t)
$$

Plotting $r_{x^{\prime}, y^{\prime}}(t)$ as a grey image, white areas indicate neuron groups with high firing rate. Drawing the outside boundaries of firing neuron groups, boundaries of moving objects are extracted.

\section{Simulation Results}

The network model was implemented in Matlab using a set of parameters for the network: $v_{t h}=-60 \mathrm{mv} . v_{\text {reset }}=-70 \mathrm{mv} . E_{e x}=0 \mathrm{mv} . E_{i h}=-75 \mathrm{mv} . E_{l}=-70 \mathrm{mv} . g_{l}=1.0$ $\mu \mathrm{s} / \mathrm{mm}^{2} . c_{m}=10 \mathrm{nF} / \mathrm{mm}^{2} . \tau_{e x}=2 \mathrm{~ms} . \tau_{i h}=3 \mathrm{~ms} . A_{i h}=0.028953 \mathrm{~mm}^{2} . A_{e x}=0.014103 \mathrm{~mm}^{2}$. These parameters can be adjusted to get good quality of output image. The architecture of simulation system is shown in Fig. 2.

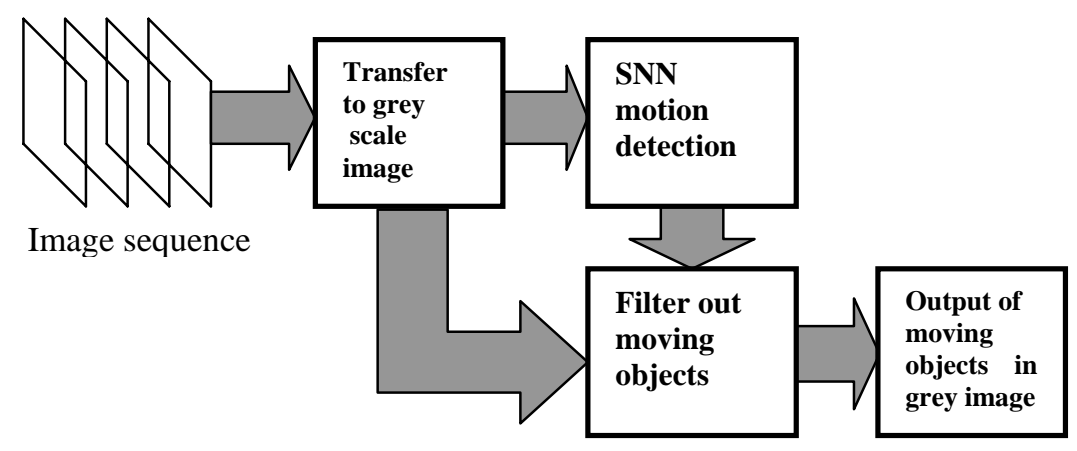

Fig. 2. The architecture of simulation system 


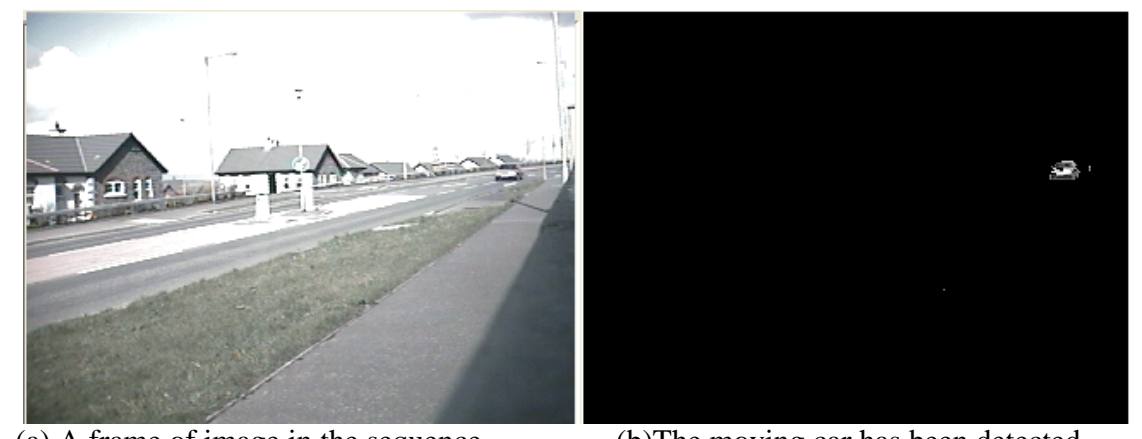

(a) A frame of image in the sequence

(b)The moving car has been detected.

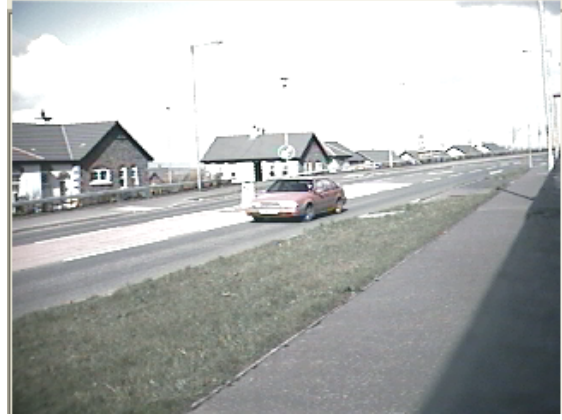

(c) Another frame from the sequence
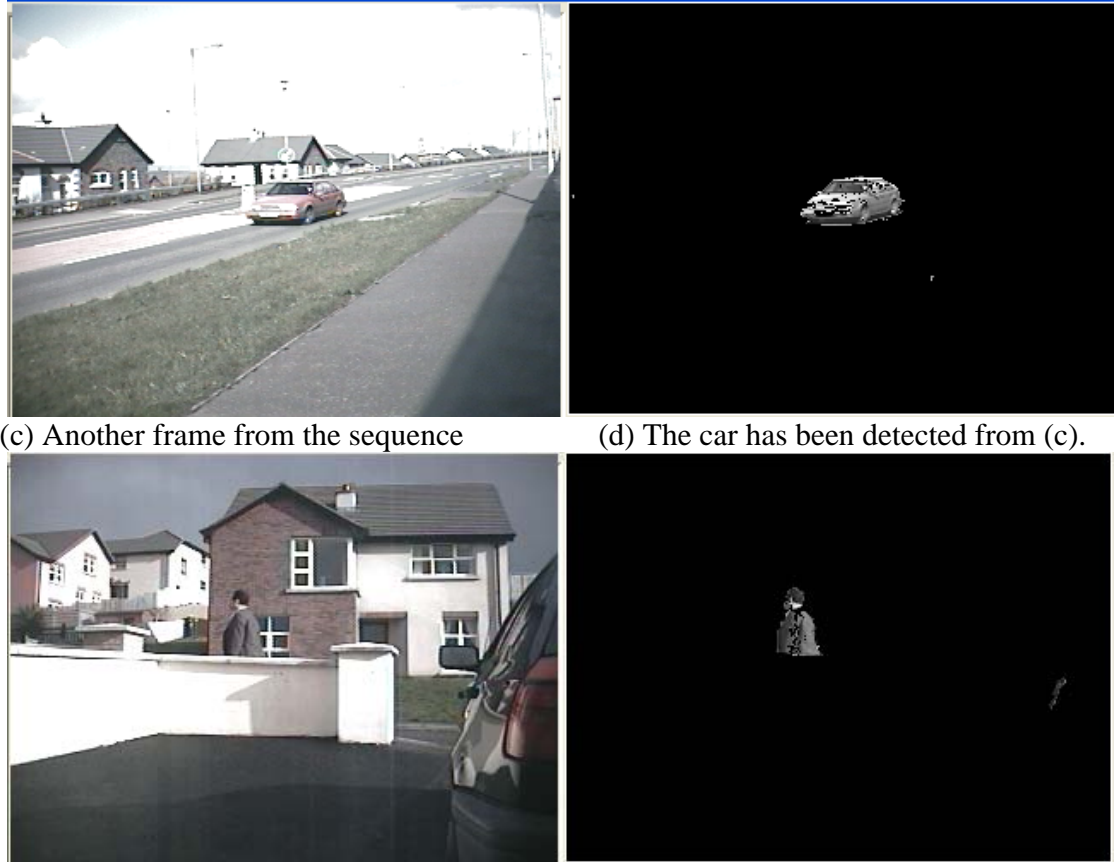

(d) The car has been detected from (c).

(e) People in an original image
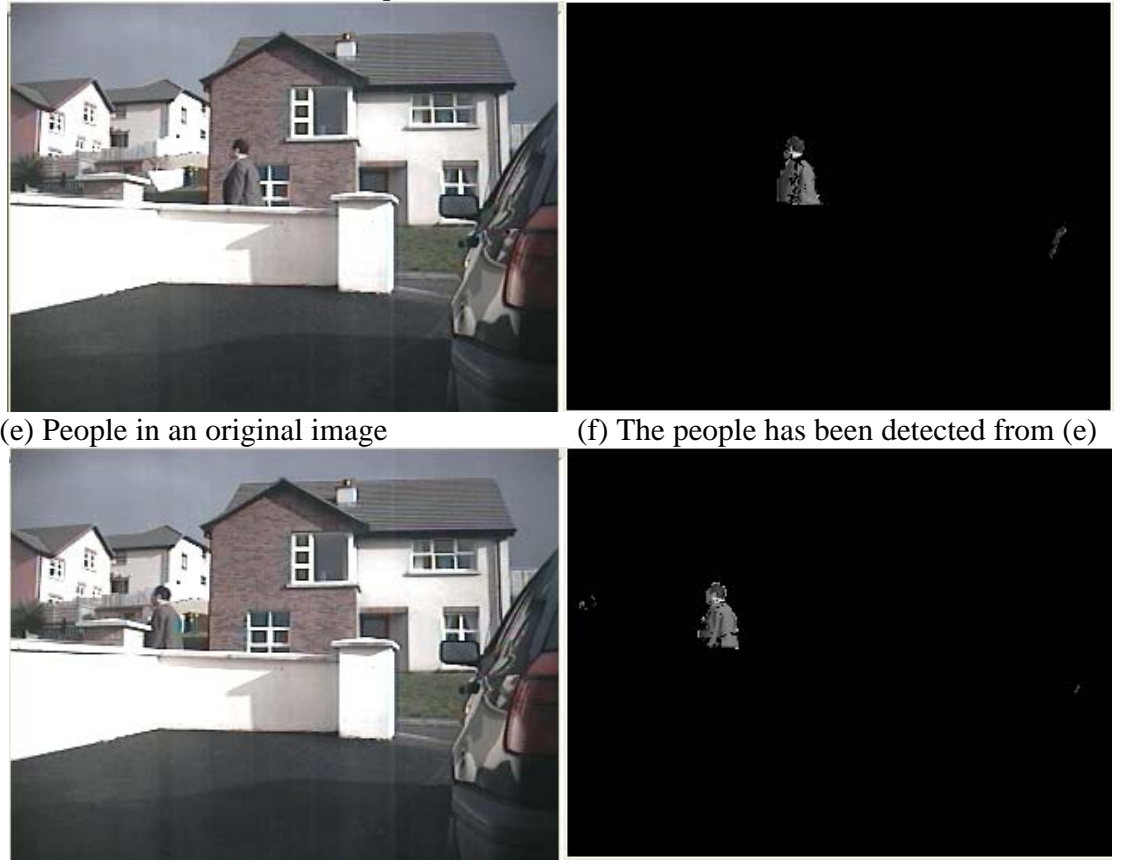

(f) The people has been detected from (e)

(g) People in an original image

(f) The people has been detected from (g)

Fig. 3. Results of simulations. 
The system takes an image from the image sequence each time step. The image is transferred to a grey scale image. The grey image presents to the spiking neural network (SNN) for motion detection. The moving objects can be detected by the SNN based on the equations in Section 3. The edges of firing neuron groups are used to determine the boundaries of the moving objects. Using the boundaries of the objects, a filter is generated to take out of moving objects from background. Therefore, the moving object in the grey image is transferred to the output image. The results of simulations are shown in Fig. 3. Images (a), (c), (e) and (g) are original image from image sequence, where as (b), (d), (f) and (h) are corresponding outputs of the simulation system. A simplified model based on the principle is implemented using $\mathrm{C}++$ in Windows XP. This program can be used to demonstrate the dynamic properties for SNN motion detection in real time.

\section{Discussion}

Inspired by biological findings, a neuronal circuit for motion detection is proposed in this paper. The neuronal circuit is based on axonal delay using spiking neuron model and it can be used to explain how a spiking neural network in the visual system can detect moving objects. Further research is required to establish the actual mechanisms employed by the visual cortex to determine motion. However, the proposal presented here can be used in artificial intelligent systems. Since the circuit is based on spiking neuron model, other findings in the human visual system can be integrated into the system to process more complicated moving objects tracking and recognition. It would be very promising to create more powerful image processing system using more biological principles found in the visual system. This is an very interesting topic for further study.

\section{References}

1. Masland, R. H., The fundamental plan of the retina. Nature Neurosci. 4(2001)877886.

2. Wassle, H. Parallel processing in the mammalian retina. Nature Rev. Neurosci. 5(2004) 747-757.

3. Nelson, R. , Kolb, H. On and off pathways in the vertebrate retina and visual system, in The Visual Neurosciences, eds Chalupa, L. M. \& Werner, J. S., MIT Press, Cambridge, MA, (2003) 260-278.

4. Demb, J. B. Cellular mechanisms for direction selectivity in the retina. Neuron 55(2007) 179-186.

5. Taylor, W. R., Vaney, D. I. New directions in retinal research. Trends Neurosci. 26(2003)379-385.

6. In-Jung Kim, Yifeng Zhang, Masahito Yamagata, Markus Meister, Joshua R. Sanes, Molecular identification of a retinal cell type that responds to upward motion, Nature 452(2008) 478 - 482. 
7. John B Reppas, Sourabh Niyogi, Anders M Dale, Martin I Sereno, Roger B H Tootell. Representation of motion boundaries in retinotopic human visual cortical areas, Nature. London:388(6638)(1997)175-186.

8. Bence P Olveczky, Stephen A Baccus, Markus Meister. Segregation of object and background motion in the retina. Nature. London: 423(6938)(2003)401-408

9. Dora E Angelaki, Aasef G Shaikh, Andrea M Green, J David Dickman. Neurons compute internal models of the physical laws of motion, Nature. London: 430(6999) (2004) 560-565.

10. Lin, J.W., Faber, D.S., Modulation of synaptic delay during synaptic plasticity. Trends Neurosci. 25(9) (2002)449-55.

11.Jose Luis Pena, Svenja Viete, Kazuo Funabiki,Kourosh Saberi, and Masakazu Konishi, Cochlear and Neural Delays for Coincidence Detection in Owls, The Journal of Neuroscience, 21(23)(2001)9455-9459.

12.Walter Senn, Martin Schneider, Berthold Ruf, Activity-Dependent Development of Axonal and Dendritic Delays, or, Why Synaptic Transmission Should Be Unreliable, Neural Computation. 14(2002)583-619.

13. Carr, C. E., Konishi, M., Axonal Delay Lines for Time Measurement in the Owl's Brainstem, Proceedings of the National Academy of Sciences of the United States of America, 85(21) 1988) 8311-8315.

14. Crook, S.M., Ermentrout, G.B., Vanier M.C. , Bower, J.M., The Role of Axonal Delay in the Synchronization of Networks of Coupled Cortical Oscillators, Journal of Computational Neuroscience, Publisher Springer Netherlands, 4(2)(1997) 15736873

15.Kandel, E. R., Shwartz, J. H.: Principles of neural science. Edward Amold (Publishers) Ltd., (1981).

16.Koch, C.: Biophysics of Computation: Information Processing in Single Neurons. Oxford University Press, (1999).

17. Dayan, P. and Abbott, L.F.: Theoretical Neuroscience: Computational and Mathematical Modeling of Neural Systems. The MIT Press, Cambridge, Massachusetts, (2001).

18.Gerstner, W., Kistler, W.: Spiking Neuron Models: Single Neurons, pulations, Plasticity. Cambridge University Press, (2002).

19.Müller, E.: Simulation of High-Conductance States in Cortical Neural Networks, Masters thesis, University of Heidelberg, HD-KIP-03-22, (2003).

20.Wu, Q.X., McGinnity, T.M., Maguire, L.P., Glackin, B., Belatreche, A.: Learning Mechanism in Networks of spiking Neurons. Studies in Computational Intelligence, Springer-Verlag, 35 (2006)171-197.

21.Wu, Q. X., McGinnity, T. M., Maguire, L. P., Belatreche, A., Glackin, B. : Adaptive Co-Ordinate Transformation Based on Spike Timing-Dependent Plasticity Learning Paradigm, LNCS, Springer, 3610 (2005)420-429.

22. Jeffress, L. A., A place theory of sound localization, J. Comp. Physiol. Psychol., 41(1948)35-39.

23. Jeffress, L. A., Binaural Phase Difference and Pitch Variation, Am. J. Psychol., 61(1948)468-486.

24. Jeffress, L. A., Interaural Phase Difference and Pitch Variation: Day-to-Day Changes, Am. J. Psychol., 62(1949)1-19. 